\title{
p53 protein expression in malignant, pre-malignant and non-malignant lesions of the lip
}

\author{
N Crosthwaite, D Teale, C Franklin, G A Foster, B M J Stringer
}

\begin{abstract}
Aim-To elucidate the role of the p53 tumour suppressor gene in the pathogenesis of lip cancer.

Methods-Expression of p53 was evaluated immunocytochemically in a retrospective study of formalin fixed, paraffin wax embedded tissue. Five cases each of four types of lip lesions were studied; these comprised squamous cell carcinoma (SCC), solar keratosis (SK), chronic hyperplastic candidosis (CHC), and lichen planus (LP). Five cases each of normal lip mucosa, SCC, and SK from sun exposed facial skin as well as LP, CHC, and SCC from buccal mucosa were also analysed. Immunolocalisation of p53 was scored semiquantitatively. The degree of apoptosis was also assessed in selected lesions by determining cell nuclear fragmentation.

Results-All SCCs from lip lesions were immunopositive for p53. All cases of SK and two of five CHC lip lesions were also p53 positive. Normal lip mucosa samples were p53 negative. Sun exposed skin lesions of SCC and SK were all positive for p53, but only three of five cases of SCC from the buccal mucosa had detectable levels of p53. p53 expression was not detected in CHC and LP lesions of the buccal mucosa.
\end{abstract}

Conclusions-The aberrant expression of p53 is likely to occur early in the pathogenesis of lip cancer and may be related to exposure to the sun. The immunopositive p53 cells identified in the benign LP lesions do not necessarily correlate with commitment of cells within the lesion to programmed cell death. In light of the prior reports which indicate that $\mathrm{p} 53$ positive cells may progress to form malignant tumours, it is suggested that patients with p53 positive but otherwise benign lesions should be followed more closely. (f Clin Pathol 1996;49:648-653)

Keywords: lip lesions, p53, benign, pre-malignant, malignant.

Altered expression of the p53 tumour suppressor gene is the most common genetic mutation found in human cancer. ${ }^{12}$ Aberrant expression of this gene often results in the build-up of the p53 protein product within affected cells, enabling it to be detected immunocytochemi- cally. However, doubts about whether p53 i overexpression is actually indicative of a p53 $\vec{\circ}$ mutational event has called into question the clinical significance of p53 immunolocalisation in pathological specimens. ${ }^{3}$ More recent elucidation of the alternative cellular caveats that can lead to the accumulation of cellular p53 in the absence of p53 mutations, ${ }^{4}$ however, provides reassurance of the value of determin- $\infty$ ing aberrant p53 expression in tissue sections 응 and has reaffirmed the clinical interest in localising p53 immunocytochemically. ${ }^{5}$

The purpose of this study was to measure p53 immunoreactivity in non-malignant, premalignant and malignant lesions of the lip. It has been shown in previous investigations that p53 overexpression occurs in $88 \%$ of 26 lip cancers; this has clearly identified a significant role for p53 in this form of malignant disease. ${ }^{6}$ In ascertaining p53 immunoreactivity in benign as well as pre-malignant lesions, this study sought to establish whether changes in p53 occur as early or late stage events in the pathogenesis of lip cancer and whether changes in p53 expression occur in non-malignant diseases of the lip. Furthermore, potential correlations between p53 immunoreactivity and a commitment to programmed cell death have been considered, for a selection of lip lesions, by assaying for DNA fragmentation in the tumour cell nuclei.

\section{Methods}

A retrospective study was performed on four $N$ different types of lip lesion: squamous cell car- $\omega$ cinoma (SCC), solar keratosis (SK), chronic hyperplastic candidosis (CHC), and lichen $\stackrel{O}{=}$ planus (LP). For each type of lesion, five $\stackrel{\oplus}{\mathcal{Q}}$ different cases were selected to give a representative sample. Similarly, five cases each 음 of SCC and SK from sun exposed facial skin, $\mathbb{D}$ and lesions of SCC, LP and CHC from buccal $\mathbb{\mathbb { D }}$ mucosa were obtained at random from the archives.

The histological criteria adopted for case $\frac{\delta}{0}$ selection were as recommended by the World Health Organisation (WHO). ${ }^{78}$ In addition, $\stackrel{0}{\overline{7}}$ for oral (including lip) LP and $\mathrm{CHC}$, the criteria were those suggested by Cawson et al. ${ }^{9}$ For both skin and oral mucosa, well differentiated (grade 1) cases of SCC were selected.

All tissues had been fixed in buffered formal saline ( $\mathrm{pH} 7.2)$ and embedded in paraffin wax. Samples of normal lip mucosa, taken from sun 
Table 1 Patient details, site and type of lesion, and grade of $p 53$ expression

\begin{tabular}{|c|c|c|c|c|c|}
\hline $\begin{array}{l}\text { Case } \\
\text { number }\end{array}$ & Sex & Age (years) & Site & Lesion & p53 grade \\
\hline 1 & $\mathbf{M}$ & 69 & Lip & SCC & 4 \\
\hline 2 & M & 61 & Lip & SCC & 4 \\
\hline 3 & $M$ & 55 & $\mathrm{Lip}$ & SCC & 3 \\
\hline 4 & $\mathbf{M}$ & 54 & $\mathrm{Lip}$ & SCC & 2 \\
\hline 5 & $\mathrm{~F}$ & 0 & $\mathrm{Lip}$ & Normal mucosa & 1 \\
\hline 6 & $\mathrm{~F}$ & 18 & Lip & Normal mucosa & 1 \\
\hline 7 & $\mathbf{M}$ & 37 & $\mathrm{Lip}$ & Normal mucosa & 1 \\
\hline 8 & M & 38 & Lip & Normal mucosa & 1 \\
\hline 9 & F & 57 & Lip & Normal mucosa & 1 \\
\hline 10 & $\mathrm{~F}$ & 35 & Lip & Normal mucosa & 1 \\
\hline 11 & $\mathbf{M}$ & 68 & Lip & $\mathrm{CHC}$ & 1 \\
\hline 12 & M & 79 & Lip & $\mathrm{CHC}$ & 2 \\
\hline 13 & $\mathrm{~F}$ & 41 & $\mathrm{Lip}$ & $\mathrm{CHC}$ & 2 \\
\hline 14 & $\mathrm{M}$ & 80 & Lip & $\mathrm{CHC}$ & 1 \\
\hline 15 & $\mathrm{~F}$ & 37 & Lip & $\mathrm{CHC}$ & 1 \\
\hline 16 & $\mathrm{~F}$ & 67 & Lip & LP & 2 \\
\hline 17 & $\mathbf{M}$ & 37 & $\mathrm{Lip}$ & LP & 2 \\
\hline 18 & M & $?$ & Lip & LP & 2 \\
\hline 19 & $\mathbf{F}$ & 67 & Lip & $\overrightarrow{L P}$ & 2 \\
\hline 20 & $\mathrm{~F}$ & 43 & $\mathrm{Lip}$ & $\overline{\mathrm{LP}}$ & 2 \\
\hline 21 & $\mathrm{~F}$ & 76 & $\mathrm{Lip}$ & SK & 2 \\
\hline 22 & $\mathbf{F}$ & 67 & Lip & SK & 3 \\
\hline 23 & $\mathrm{~F}$ & 64 & Lip & SK & 3 \\
\hline 24 & $M$ & 66 & $\mathrm{Lip}$ & SK & 2 \\
\hline 25 & M & 58 & $\mathrm{Lip}$ & SK & 2 \\
\hline 26 & $\mathbf{M}$ & 81 & Skin & SCC & 4 \\
\hline 27 & $\mathbf{M}$ & 79 & Skin & SCC & 2 \\
\hline 28 & $\mathbf{M}$ & 84 & Skin & SCC & 2 \\
\hline 29 & M & 79 & Skin & SCC & 2 \\
\hline 30 & M & 84 & Skin & SCC & 3 \\
\hline 31 & $\mathbf{M}$ & 76 & Skin & SK & 4 \\
\hline 32 & $\mathbf{M}$ & 72 & Skin & SK & 3 \\
\hline 33 & M & 58 & Skin & SK & 3 \\
\hline 34 & $\mathbf{M}$ & 74 & Skin & SK & 2 \\
\hline 35 & $\mathbf{M}$ & 70 & Skin & SK & 2 \\
\hline 36 & $\mathrm{~F}$ & 67 & Buccal mucosa & SCC & 3 \\
\hline 37 & $\mathrm{~F}$ & 69 & Buccal mucosa & SCC & 3 \\
\hline 38 & $\mathbf{M}$ & 50 & Buccal mucosa & SCC & 2 \\
\hline 39 & $\mathbf{M}$ & 66 & Buccal mucosa & SCC & 1 \\
\hline 40 & $\mathbf{F}$ & 63 & Buccal mucosa & SCC & 1 \\
\hline 41 & $\mathrm{M}$ & 64 & Buccal mucosa & $\mathrm{LP}$ & 1 \\
\hline 42 & $\mathrm{~F}$ & 39 & Buccal mucosa & LP & 1 \\
\hline 43 & $\mathrm{~F}$ & 29 & Buccal mucosa & LP & 1 \\
\hline 44 & $\mathrm{~F}$ & 67 & Buccal mucosa & LP & 1 \\
\hline 45 & $\mathrm{~F}$ & 29 & Buccal mucosa & LP & 1 \\
\hline 46 & M & 43 & Buccal mucosa & $\mathrm{CHC}$ & 1 \\
\hline 47 & $\mathrm{M}$ & 68 & Buccal mucosa & $\mathrm{CHC}$ & 1 \\
\hline 48 & $\mathrm{~F}$ & 31 & Buccal mucosa & $\mathrm{CHC}$ & 1 \\
\hline 49 & $\mathrm{~F}$ & 56 & Buccal mucosa & $\mathrm{CHC}$ & 1 \\
\hline 50 & F & $?$ & Buccal mucosa & $\mathrm{CHC}$ & 1 \\
\hline
\end{tabular}

Table 2 Lip lesions by type and grade

\begin{tabular}{llllll}
\hline Grade & SCC & $S K$ & CHC & LP & Normal mucosa \\
\hline 1 & 0 & 0 & 3 & 0 & 5 \\
2 & 1 & 3 & 2 & 5 & 0 \\
3 & 1 & 2 & 0 & 0 & 0 \\
4 & 3 & 0 & 0 & 0 & 0
\end{tabular}

Table 3 Lesions from sun exposed skin tissue by type and grade

\begin{tabular}{lll}
\hline Grade & SCC & $S K$ \\
\hline 1 & 0 & 0 \\
2 & 3 & 2 \\
3 & 1 & 2 \\
4 & 1 & 1 \\
\hline
\end{tabular}

exposed tissue overlying mucous extravasation cysts, were also obtained.

Breast tumour tissue which had previously been identified as p53 immunopositive was used as a positive control.

\section{IMMUNOCYTOCHEMISTRY}

Sections, $5 \mu \mathrm{m}$ thick, were cut from representative paraffin wax blocks of the aforementioned lesions and from the known immuno-
Table 4 Lesions from buccal mucosa by type and grade

\begin{tabular}{llll}
\hline Grade & $S C C$ & $C H C$ & $L P$ \\
\hline 1 & 2 & 5 & 5 \\
2 & 1 & 0 & 0 \\
3 & 2 & 0 & 0 \\
4 & 0 & 0 & 0 \\
\hline
\end{tabular}

negative and immunopositive controls. Control tissue was run for each immunocytochemical experiment.

Samples were subjected to an indirect immunoperoxidase technique to localise p53 as follows: sections were mounted on poly-Llysine coated slides and allowed to dry in air overnight at room temperature as the use of heat at this stage is not recommended. ${ }^{10}$ Sections were dewaxed in xylene, ethanol and $70 \%$ ethanol. Endogenous peroxidase activity was blocked by submerging sections in a $5: 1$ (v/v) solution of methanol:10 $\mathrm{mM}$ phosphate buffered saline (PBS), $\mathrm{pH} 7.6$, containing $0.3 \%$ hydrogen peroxide for 30 minutes. Sections were then washed in PBS for $10 \mathrm{~min}$ utes during which the PBS solution was changed three times. This washing procedure was carried out between each new application of reagents.

Where CM-1 (Novocastra Laboratories, Newcastle, UK) was used as primary antiserum, non-specific binding was blocked by first incubating the sections with normal goat serum (Vectastain ABC kit, Vector Laboratories, Peterborough, UK) diluted in PBS for 30 minutes. Excess serum was blotted away and primary antiserum, diluted 1 in 1500 in PBS containing $0.01 \%$ Tween 20 , was applied. The sharpest intensity and most consistent results were obtained by overnight incubation at $4^{\circ} \mathrm{C}$. Sections were then incubated with the goat anti-rabbit secondary antibody followed by avidin peroxidase, according to the manufacturer's instructions.

In addition, a pre-diluted mouse monoclonal antibody directed against p53 (IOpath, Immunotech International, Birmingham, UK) was used in place of the CM-1 primary antiserum. In this procedure, sections were first pretreated in a microwave oven in $10 \mathrm{mM}$ citrate buffer, $\mathrm{pH}$ 6.0. After cooling for five minutes, the microwave treatment was repeated and sections allowed to cool to room temperature. They were then rinsed in PBS and incubated with the mouse monoclonal antibody directed against p53 at room temperature for one hour. This was followed by incubation with biotinylated horse anti-mouse secondary antiserum and avidin peroxidase according to the manufacturer's instructions (Vector Laboratories).

For both procedures, after washing the slides in PBS, reaction products were developed by immersion of the sections (for an appropriate length of time to allow the development of a colour reaction product, but keeping background staining to a minimum) in equal volumes of $0.1 \%$ diaminobenzidine tetrahydrochloride (DAB), made in $0.1 \mathrm{M}$ Tris buffer, $\mathrm{pH}$ 7.2 , and $0.02 \%$ hydrogen peroxide (made in distilled water from a $30 \% \quad \mathrm{H}_{2} \mathrm{O}_{2}$ stock 


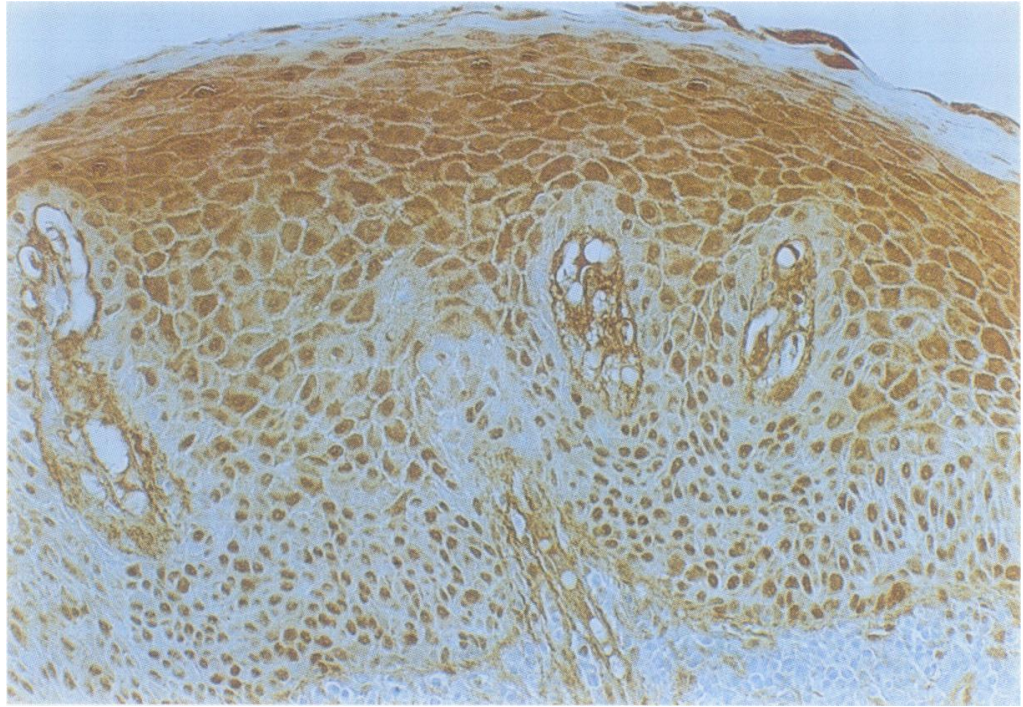

Figure 1 Chronic hyperplastic candidosis of the lip showing $p 53$ localisation in the basal and parabasal layers of the epithelium. Non-specific cytoplasmic staining is also seen and is possibly due to antiserum cross reactivity with keratins. CM-1 antiserum (Novocastra) and Harris's haematoxylin counterstain $(\times 200)$.

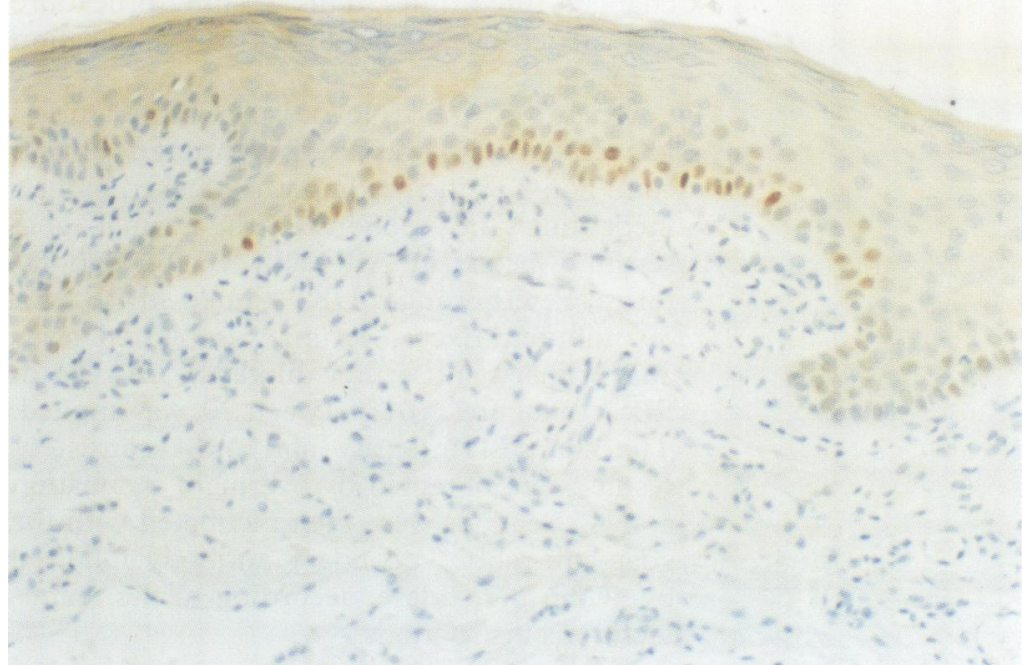

Figure 2 p53 immunopositivity in the epithelial basal cells in the lichen planus of the lip identified using a monoclonal antibody directed against p53 (IOpath). Harris's haematoxylin counterstain $(\times 200)$.

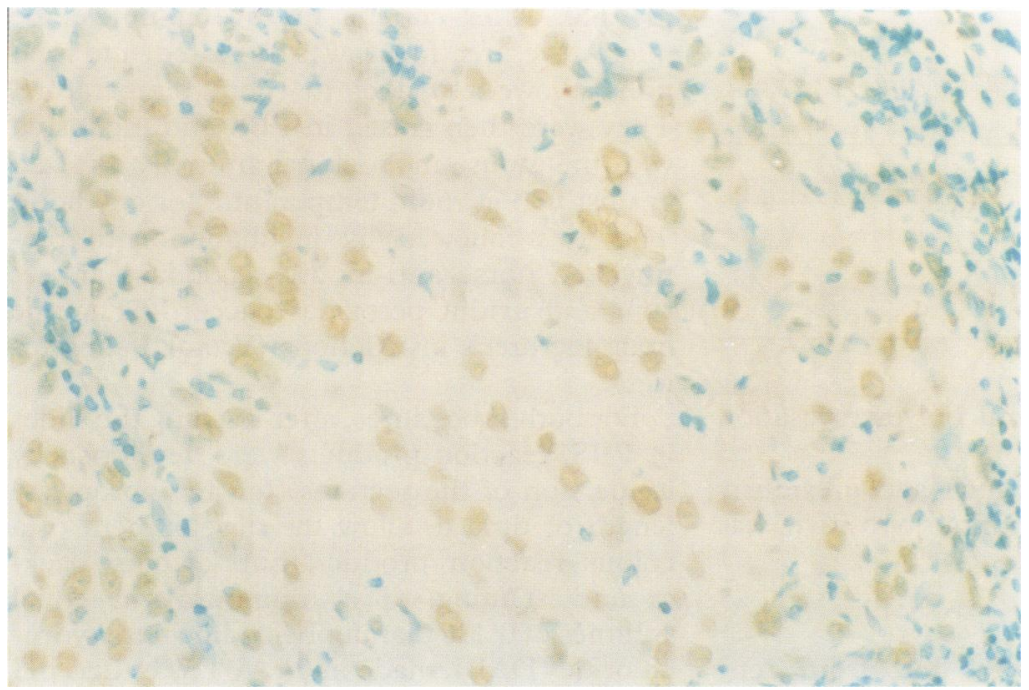

Figure 3 Nuclear fragmentation in a squamous cell carcinoma of the lip detected by $3^{\prime}$ end nucleotide labelling (ApopTag). Methyl green counterstain $(\times 400)$. solution). Slides were then immersed in running tap water for five minutes, lightly counterstained in Harris's haematoxylin, dehydrated, cleared, and mounted.

For each immunocytochemical run the $c$ following were used: (1) two negative control $\overline{5}$ sections, one with the primary antibody, the 0 other with PBS alone; and (2) two sections of a $\vec{F}$ p53 positive breast tumour, treated as de- $\frac{}{.}$ scribed above.

\section{SEMIQUANTITATIVE ANALYSIS}

Interpretation of staining was based on a semi- $\bar{c}$ quantitative grading system, as described $\vec{D}$ previously. ${ }^{10} 11$ The proportion of cells with immunoreactive p53 were scored as follows: grade $1=$ no staining; grade $2=<10 \%$ of tumours cells p53 positive; grade $3=10-70 \%$ tumour cells p53 positive; grade $4=>70 \%$ tumour cells p53 positive. Sections were exam- 용 ined in a double blind manner to reduce bias $\overrightarrow{0}$ and ensure consistency of examination.

LABELLING OF APOPTOTIC CELLS

To determine cellular commitment to apoptosis in tissue samples, the method of terminal deoxynucleotidyl transferase (TDTase) catalysis was used, by way of an apoptosis detection kit (ApopTag, Oncor Inc., Gaithersburg, USA).

Sections were incubated in the presence of digoxigenin labelled d-UTP and d-ATP, and TDTase. The 3' ends of DNA are recognised by TDTase which catalytically replaces short sequences from the exposed 3 ' end by up to 11 nucleotides. This ensures that all fragmented DNA, which is present abundantly in cells undergoing apoptosis, is labelled with digoxigenin. After being washed in PBS, sections were incubated with immunoperoxidase labelled anti-digoxygenin antibody, followed by labelling with $\mathrm{DAB}$ as described earlier.

\section{Results}

IMMUNOLOCALISATION OF P53

The p53 related immunohistochemical results are summarised in table 1 . Tables 2,3 , and 4 provide a breakdown of lesions and grading by site.

The expression of immunoreactive p53 phosphoprotein was analysed in 50 independ- N ent cases; 30 of these exhibited positive 0 staining to some degree. The reaction product, 0 which denoted the binding of CM-1 antiserum (or monoclonal antibody directed against $\stackrel{\circ}{\rightarrow}$ p53), was localised to cell nuclei. Generally, 꿍 p53 positive nuclei were stained homogeneously, but with varying intensity. A more $\stackrel{\odot}{\oplus}$ granular pattern was observed occasionally in some lesions. However, there was no discernible relation between staining intensity or o pattern of nuclear staining and the type of lesion.

The CM-1 antiserum showed a degree of cross reactivity with the keratins. This made it difficult to assess the rating of some lesions, particularly for well differentiated SCCs which produce keratin. In contrast, staining was localised to cell nuclei in poorly differentiated SCCs. Problems with CM-1 were circum- 
vented, however, by the additional use of a p53 monoclonal antibody which has negligible cross reactivity with the cytokeratins.

In this investigation all the cases of SCC from sun exposed lip and skin were positive for p53, as were three lesions of SCC from buccal mucosa. Three SCCs from the lip and one from the skin scored grade 4 and all were widely invasive lesions. It was noted that SCCs which were widely invasive represented the best examples of distinct, intense nuclear p53 overexpression, particularly in the cells found in more deeply invasive malignant epithelium. Focal areas of basal and parabasal p53 immunolocalisation in adjacent normal or even hyperplastic epithelium was also a consistent finding in SCC sections.

Solar keratosis is regarded as a potential premalignant lesion and tables 2 and 3 highlight the high degree of p53 overexpression exhibited in all SK lip and skin lesions examined. One SK lesion from sun exposed skin gave an unusual result in that p53 expression was absent from the epidermis but was present in dermal fibroblasts. In addition, some, but not all, of the SK specimens (from both lip and
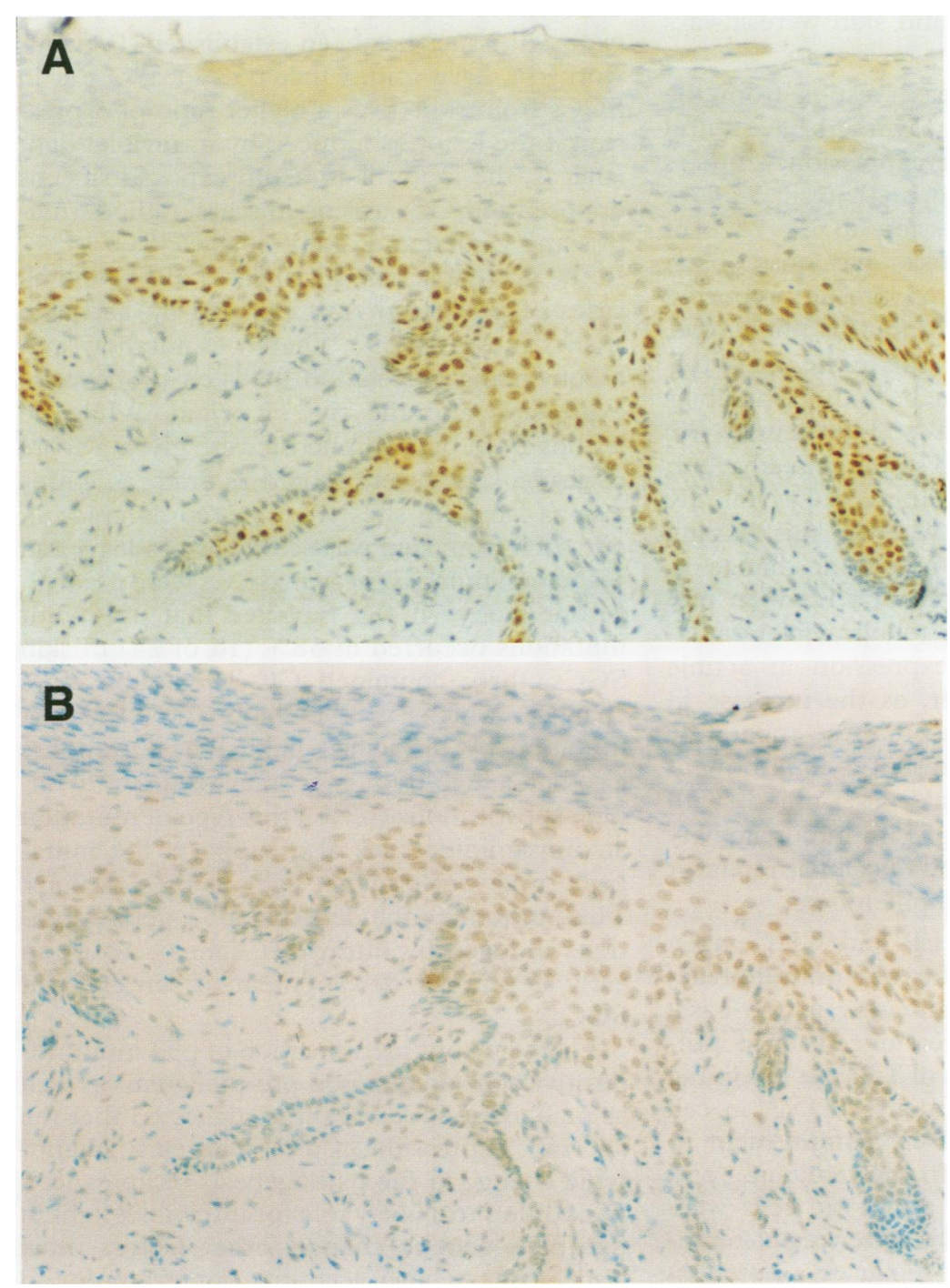

Figure 4 (A) p53 immunopositivity in an area of hyperplasia in solar keratosis of the lip identified using a monoclonal antibody directed against p53 (IOpath). Harris's

haematoxylin counterstain $(\times 200)$. (B) Serial section to that depicted in $(A)$ showing the distribution of apoptotic cells by $3^{\prime}$ end nucleotide labelling (ApopTag). Methyl green counterstain $(\times 200)$. skin) also provided examples of a distinct cutoff point between tissue expressing p53 and normal p53 negative adjacent tissue and some showed p53 positive staining in adjacent, apparently normal epithelium.

Lesions from patients with CHC of buccal mucosa did not express p53; however, two of the five CHC lesions from lip tissue did (fig 1). Within these two lesions p53 staining was focal and some areas were given an overall score of grade 3, whereas in other areas of the same lesion p53 expression was absent.

Cases of LP were included in this study as known benign lesions with minimal potential for malignant change. All of the LP lesions of the buccal mucosa were p53 negative, however, all five LP lesions of the lip showed some degree of p53 immunopositivty localised to the basal layer. Staining was very weak in three cases, and only identifiable in some basal cells in two of these (fig 2).

All samples of normal lip mucosa were p53 negative.

DNA FRAGMENTATION STUDIES

In order to distinguish whether p53 immunopositivity signified a commitment to programmed cell death, a selection of p53 immunopositive lesions was analysed for nuclear DNA fragmentation, a marker of cellular apoptosis. These included SCC, SK and LP lesions of the lip.

Considerable variability was seen both between and within the SCC lesions sampled. In some tumours, no nuclear DNA fragmentation could be detected. However, in some up to $50 \%$ of cells were undergoing apoptosis in what seemed to be a random fashion, whereas in some other SCC lesions, nuclear fragmentation was restricted to the periphery of the tumour mass (fig 3).

Three of the SK lesions of the lip showed a similar proportion of cells with nuclear DNA cleavage to their p53 staining; this was localised to the basal layer. In one of the three lesions, however, p53 was localised to an area of hyperplasia (fig 4A), but the apoptotic cells were also seen in a similar distribution (fig 4B).

Of the five LP lesions of the lip, four showed nuclear fragmentation which had a more diffuse localisation in all layers of the epithelium (fig 5).

\section{Discussion}

To our knowledge, this study provides the first analysis of p53 protein expression in benign and pre-malignant lip lesions. In addition, we have measured p53 immunoreactivity in a series of lip SCCs; for comparison, skin and buccal mucosa biopsy specimens provided examples of sun exposed and non-sun exposed tissue, respectively.

Results obtained from the intra-oral malignancies are similar to those of other workers and show that p53 localisation is variable both in terms of expression and the degree of nuclear intensity. ${ }^{12-17}$ To date, it seems that there is no oral site in normal or lesional tissue that is specific for $\mathrm{p} 53$ positivity. In one $s t u d y^{17}$ a correlation between p53 expression and 


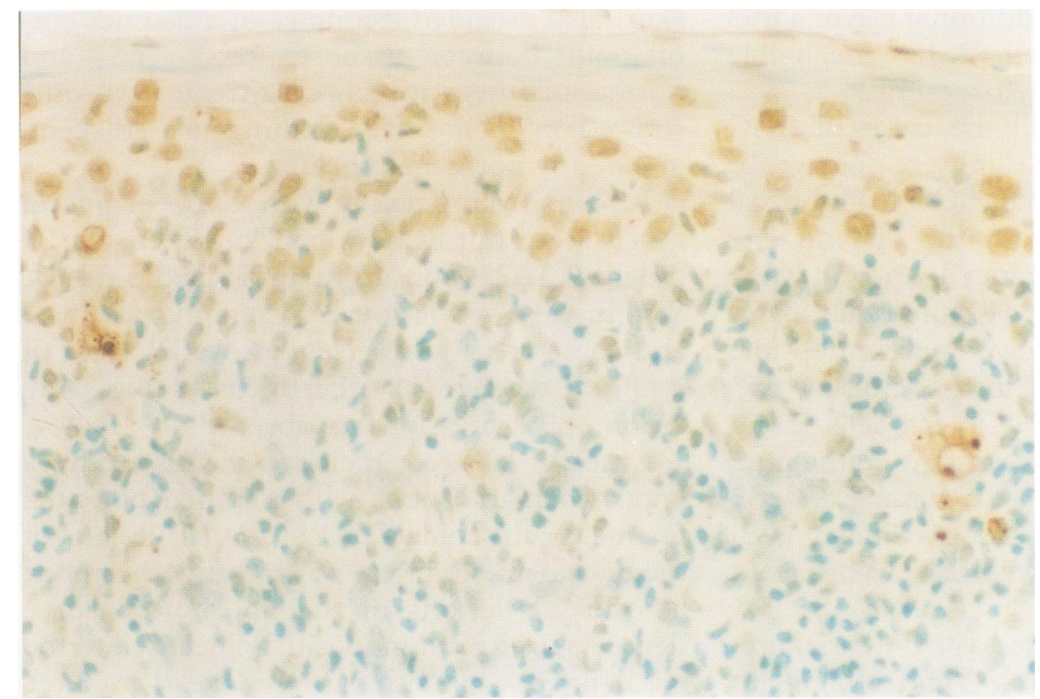

Figure 5 Lichen planus of the lip showing nuclear fragmentation throughout many of the epithelial layers by $3^{\prime}$ end nucleotide labelling (ApopTag). Methyl green counterstain $(\times 200)$ sia and lesions which can become malignant at a later date. For example, one longitudinal study of a patient's dorsal lingual hyperkeratosis found no p53 overexpression in 1986, yet in 1987 and 1989 positive results for p53 were obtained when clearly there was no histopathological evidence of dysplasia. Examination of a subsequent biopsy specimen in 1991 resulted in a diagnosis of carcinoma in situ. ${ }^{24}$ Furthermore, from a recent prospective study, there is now good evidence of the clinical value of p53 immunohistochemical data. ${ }^{25}$ In the latter study, Dowell et al determined p53 expression in 1333 non-gynaecological cytological specimens without prior knowledge of the diagnosis. Of 108 cases of p53 overexpression, 86 proved to be malignant lesions. Of 43 cytopathologically suspicious lesions, seven were found to exhibit p53 expression; all seven cases were eventually diagnosed as malignant. It might be deduced from these studies, therefore, that the presence of immunoreactive p53 in lip lesions is indicative of a potential for malignant change. Hence, the presence of p53 immunoreactivity in apparently benign LP lesions of the lip might be a useful indicator that such lesions should be viewed with greater

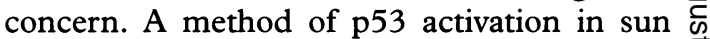
exposed tissues has been established. Previous $\vec{\theta}$ workers ${ }^{26}$ have found that p53 localisation in 8 SCCs from skin gives a higher ratio of expression if the lesion is induced by ultraviolet light (that is, the lesion is in a sun exposed site) as opposed to SCCs arising in scars, radiodermatitis and genital and oral lesions (54\% v 19\%). In the present series, all 10 cases of SK and all cases of SCC from sun exposed lip and skin tissues expressed p53. There was not, however, a convincing correlation between the level of expression and the site of origin. While no lesions from buccal mucosa were given a score ? of grade 4 , two were scored as grade 3 . Three lesions from lip sites were scored as grade 4 , one each from skin was scored as grades 3 and 4 ; the remaining three skin SCCs were grade 2 . In one study ${ }^{27}$ it was reported that p53 point mutations occurred in $58 \%$ (14 of 24 ) of skin $\frac{D}{0}$ SCCs, three contained CC-TT double base changes which is the hallmark of DNA o mutation by ultraviolet light. These tumours $N$ also had a high frequency of cytosine to thymi- N dine substitutions $(62 \%)$; this type of mutation 0 at dipyrimidine sites also supports the muta- 0 genic role of ultraviolet light in these lesions. The authors concluded that p53 gene mutations induced by ultraviolet light occur as an early step in the development of sun exposed SCCs.

Following our identification of p53 immunopositivity in sun exposed pre-malignant as well as malignant lip lesions it is suggested that the $\delta$ aberrant expression of $\mathrm{p} 53$ is an early phenotypic change in the pathogenesis of lip cancer. In addition to a likely role for ultraviolet light in $\stackrel{?}{\rightleftharpoons}$ this pathogenetic change, other factors must also be taken into account. For example, an association between heavy drinking and smoking with raised p53 expression has been established. ${ }^{28}$ Tobacco is a known carcinogenic agent and has been implicated in the pathogen-

So far, clinical studies have shown that p53 protein expression correlates with both neopla- 
esis of lip cancer. ${ }^{29}$ Viruses may also play a role in this rise in $\mathrm{p} 53$ expression. ${ }^{30}$

In conclusion, we have localised p53 immunocytochemically in malignant, pre-malignant and non-malignant lesions of the lip. From our results, it is suggested that aberrant p53 expression is likely to be an early event in the pathogenesis of lip cancer. Furthermore, we have shown that the immunopositive p53 cells identified in the benign LP lesions do not necessarily correlate with a commitment of cells within the lesion to programmed cell death. In light of the prior reports which indicate that p53 positive cells may progress to form malignant tumours, ${ }^{24}{ }^{25}$ we suggest that patients with p53 positive but otherwise benign lesions should be followed more closely.

We are grateful to the Yorkshire Cancer Research Campaign for funding this work, and to Mr David Thompson for helping with photography.

1 Hollstein M, Sidransky D, Vogelstein B, Harris CC. p53 mutations in human cancers. Science 1991;253:49-53.

2 Nigro JM, Baker SJ, Preisinger AC, Jessup JM, Hostetter R, Cleary $\mathrm{K}$, et al. Mutations in the p 53 gene occur in diverse Cleary K, et al. Mutations in the p53 gene occur

3 Wynford-Thomas D. p53 in tumour pathology: can we trust immunohistochemistry? f Pathol 1992;166:329-30.

4 Wu X, Boyle JH, Olson DC, Levine AJ. The p53-mdm2 autoregulatory feedback loop. Genes Dev 1993;7:1126-32. 5 Hall PA, Lane DP. p53 in tumour pathology: can we trus immunohistochemistry? - revisited! f Pathol 1994;172:1-4.

6 Berner A, Holm R, Arne N, Hjortdal O. p53 protein expression in squamocellular carcinomas of the lip. Anticancer Res 1993;13:2421-4.

7 Ten Seldam REJ, Helwig EB, Sobin LH, Torlini $\mathrm{H}$ Histological typing of skin tumours. International Histo-
logical Classification of Tumours. No. 12. Geneva: World logical Classification of Tum

8 Wahi PN, Cohen B, Luthra UK, and Torlini H. Histological typing of oral and oropharyngeal tumours. International Histological Classification of Tumours. No. 4. Geneva World Health Organisation, 1971.

9 Cawson RA, Binnie WH, Eveson JW. Colour atlas of oral disease. 2nd edn. London: Wolfe, 1994.

10 Pavelic ZP, Portugal LG, Goote MJ, Stambrook PJ, Smith C, Mugge RE, et al. Retrieval of p53 protein in paraffin-embedded head and neck tumour tissur

11 Vojtesek B, Bartek J, Midgeley CA, Lane DP. An immunohistochemical analysis of the human nuclear phosphoprotein p53. New monoclonal antibodies and epitope mapping using recombinant p53. F Immunol Methods 1992;151:237-44.

12 Ogden GR, Kiddie RA, Lunny DP, Lane DP. Assessment of p53 protein expression in normal, benign and malignant oral mucosa. f Pathol 1992;166:389-94.
13 Sakai E, Tsuchida N. Most human squamous cell carcinomas in the oral cavity contain p53 tumour suppressor genes. Oncogene 1992;7:927-33.

14 Warnakulasuriya KAAS, Johnson NW. Expression of p53 mutant nuclear phosphoprotein in oral carcinoma and potentially malignant oral lesions. F Oral Pathol Med 1992;
21:404-8.

15 Warnakulasuriya KAAS, Johnson NW. Association of over-expression of p53 oncoprotein with the state of cell proliferation in oral carcinoma. I Oral Pathol Med 1994;23:246-50

16 Matthews JB, Scully C, Jovanovic A, Van der Waal, Yeudall WA, Prime SS. Relationship of tobacco-alcohol use to p53 expression in patients with lingual squamous cell carcinomas. Eur 7 Cancer 1993;29B:285-9.

17 Nishioka H, Hiasa Y, Hayashi I, Kitahori Y, Konishi N, Sugimura M. Immunohistochemical detection of p53 oncoprotein in human oral squamous cell carcinomas and leukoplakias: comparison with proliferating cell nuclear antigen staining and correlation with clinicopathological findings. Oncology 1993;50:426-9.

18 Gusterson BA, Anbazhagen R, Warren W, Midgely C, Lane DP, O'Hare M, et al. Expression of $\mathrm{p} 53$ in premalignant and malignant squamous epithelium. Oncogene 1991; 6:1785-9.

19 Sims CS, Slater S, McKee PH. Mutant p53 expression in solar keratosis: an immunohistochemical study. $\mathcal{f}$ Cutan Pathol 1992;19:302-8.

20 Urano Y, Oura H, Sakaki A, Nagae H, Matsumoto K, Fukuhara $\mathrm{K}$, et al. Immunohistochemical analysis of p53 expression in human skin tumours. $f$ Dermatol $S_{c i}$ 1992;4:69-75.

21 Ro YS, Cooper PN, Lee JA, Quinn AG, Harrison D, Lane $\mathrm{DP}$, et al. p53 protein expression in benign and malignant skin tumours. Br 7 Dermatol 1993;128:237-41.

22 Gannon JV, Greaves R, Iggo R, Lane DP. Activating mutations in $\mathrm{p} 53$ produce a common conformational effect. A monoclonal antibody specific for the mutant form. $E M B O$ f 1990;9: 1595-602.

23 Hall PA, McKee PH, Du Menage HD, Dover R, Lane DP. High levels of $\mathrm{p} 53$ protein in UV-irradiated normal human skin. Oncogene 1993;8:203-7.

24 Ogden GR, Lane DP, Chisholm DM. p53 expression in dyskeratosis congenita: a marker for oral premalignancy? $\mathcal{F}$ Clin Pathol 1993;46:169-70.

25 Dowell SP, Wilson PO, Derias NW, Lane DP, Hall PA. Clinical utility of the immunocytochemical detection of p53 protein in cytological specimens. Cancer Res 1994;54: 2914-18.

26 Nagano $Y$, Ueda $M$, Ichihashi $M$. Expression of $\mathrm{p} 53$ protein is an early event in ultraviolet light-induced cutaneous squamous cell carcinogenesis. Arch Dermatol 1993; 129:1157-61.

27 Brash DE, Rudolph JA, Simon JA, Lin A, McKenna GT, Baden HP, et al. A role for sunlight in skin cancer: UV-induced p 53 mutations in squamous cell carcinoma. Proc Natl Acad Sci USA 1991;88:10124-8.

28 Field JK, Spandidos DA, Stell PM. Over-expression of the p53 gene in head and neck cancer, linked with heavy smoking and drinking. Lancet 1992;339:502-3.

29 Blomqvist G, Hirsch JM, Alberius P. Association between development of lower lip cancer and tobacco habits. F Oral Maxillofac Surg 1991;10:1044-7.

30 Levine AJ, Momand J, Finlay CA. The p53 tumour suppressor gene. Nature 1991;351:453-6. 